\title{
Article
}

\section{Biotransformation of chrysin to baicalein: Selective C6- hydroxylation of 5,7-dihydroxyflavone using whole yeast cells stably expressing human CYP1A1 enzyme}

Ibidapo S Williams, Shifali Chib, Vijay Nuthakki, Linda Gatchie, Prashant Joshi, Niteen

Narkhede, Ram A. Vishwakarma, Sandip B. Bharate, Saurabh Saran, and Bhabatosh Chaudhuri

J. Agric. Food Chem., Just Accepted Manuscript • DOI: 10.1021/acs.jafc.7b02690 • Publication Date (Web): 07 Aug 2017

Downloaded from http://pubs.acs.org on August 8, 2017

\section{Just Accepted}

"Just Accepted" manuscripts have been peer-reviewed and accepted for publication. They are posted online prior to technical editing, formatting for publication and author proofing. The American Chemical Society provides "Just Accepted" as a free service to the research community to expedite the dissemination of scientific material as soon as possible after acceptance. "Just Accepted" manuscripts appear in full in PDF format accompanied by an HTML abstract. "Just Accepted" manuscripts have been fully peer reviewed, but should not be considered the official version of record. They are accessible to all readers and citable by the Digital Object Identifier (DOI®). "Just Accepted" is an optional service offered to authors. Therefore, the "Just Accepted" Web site may not include all articles that will be published in the journal. After a manuscript is technically edited and formatted, it will be removed from the "Just Accepted" Web site and published as an ASAP article. Note that technical editing may introduce minor changes to the manuscript text and/or graphics which could affect content, and all legal disclaimers and ethical guidelines that apply to the journal pertain. ACS cannot be held responsible for errors or consequences arising from the use of information contained in these "Just Accepted" manuscripts. 

Biotransformation of chrysin to baicalein: Selective C6-

3 hydroxylation of 5,7-dihydroxyflavone using whole yeast

\section{cells stably expressing human CYP1A1 enzyme}

5 Ibidapo S. Williams, ${ }^{\dagger,}, \#$ Shifali Chib, ${ }^{\S, \#}$ Vijay Nuthakki, ${ }^{\perp *}$ Linda Gatchie, ${ }^{\dagger, \downarrow}$ Prashant Joshi, ${ }^{\perp}$ Niteen A.

6 Narkhede, ${ }^{\|}$Ram A. Vishwakarma, ${ }^{\perp}$ Sandip B. Bharate, ${ }^{\perp, \phi, *}$ Saurabh Saran,,${ }^{\S} *$ Bhabatosh Chaudhuri ${ }^{*}, \dagger, \dot{\dagger}$

$7 \quad$ \# Contributed equally to this work as a first author.

$8 \quad \dagger$ Leicester School of Pharmacy, De Montfort University, Leicester, LE1 9BH, UK

$9{ }^{\ddagger}$ CYP Design Limited, Innovation Centre, 49 Oxford Street, Leicester, LE1 5XY, UK

$10{ }^{\S}$ Fermentation Technology Division, CSIR-Indian Institute of Integrative Medicine, Canal Road,

11 Jammu-180001, India.

$12 \perp$ Medicinal Chemistry Division, CSIR-Indian Institute of Integrative Medicine, Canal Road, Jammu13 180001, India

14 "Instrumentation Division, CSIR-Indian Institute of Integrative Medicine, Canal Road, Jammu-180001, 15 India

$16{ }^{\phi}$ Academy of Scientific \& Innovative Research (AcSIR), CSIR-Indian Institute of Integrative Medicine,

17 Canal Road, Jammu-180001, India

18 


\section{ABSTRACT:}

22 Naturally occurring polyphenolic compounds are of medicinal importance because of their unique

23 antioxidant, anticancer and chemopreventive properties. Baicalein, a naturally occurring polyhydroxy

24 flavonoid possessing a diverse range of pharmacological activities, has been used in traditional

25 medicines for treatment of various ailments. Apart from its isolation from natural sources, its synthesis

26 has been reported via multi-step chemical approaches. Here we report a preparative-scale

27 biotransformation, using whole yeast cells stably expressing human cytochrome P450 1A1 (CYP1A1)

28 enzyme, that allows regioselective C6-hydroxylation of 5,7-dihydroxyflavone (chrysin) to form 5,6,7-

29 trihydroxyflavone (baicalein). Molecular modelling reveals why chrysin undergoes such specific

30 hydroxylation mediated by CYP1A1. More than $92 \%$ reaction completion was obtained using a shake-

31 flask based process that mimics fed-batch fermentation. Such highly efficient selective hydroxylation,

32 using recombinant yeast cells, has not been reported earlier. Similar CYP-expressing yeast cell-based

33 systems are likely to have wider applications in the syntheses of medicinally important polyphenolic

34 compounds.

36 Keywords: Biotransformation, chrysin, baicalein, CYP1A1, yeast cells, hydroxylation 


\section{INTRODUCTION}

Baicalein (5,6,7-trihydroxyflavone) (1) was originally isolated from the roots of Scutellaria baicalensis (Chinese skullcap) which is used for treatment of chronic hepatitis, inflammatory diseases, tumors, and diarrhea in China, Korea, Taiwan, and Japan. ${ }^{1}$ Its isolation has also been reported from another plant, Oroxylum indicum (Indian trumpet flower). ${ }^{2}$ Baicalein is known for its anticancer properties in various cancer types $^{2-22}$ including pancreatic, gastric and colorectal cancers, multiple myeloma, head and neck

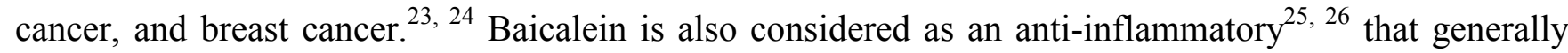
protects against oxidative stress, ${ }^{27}$ more specifically in cardiac cells, ${ }^{28}$ and in cisplatin-induced acute kidney injury. ${ }^{29}$ Because of its wide-ranging medicinal applications, an industrial scale protocol for its production would be considered as important.

Baicalein has primarily been produced via five approaches: (a) single-step hydrolysis of the natural product baicalin, a glycoside, ${ }^{30}$ (b) 4-step total synthesis from a cinnamic acid derivative, ${ }^{31}$ (c) 4-step total synthesis from 3,4,5-trimethoxyphenol, ${ }^{32}$ (d) 3-step total synthesis from 2,4,5,6tetrahydroxyacetophenone, ${ }^{33}$ and (e) 6-step synthesis from chrysin ${ }^{34}$ involving methylation, bromination, acylation, nucleophilic replacement of $\mathrm{Br}$ with $\mathrm{OMe}$, followed by de-acylation and demethylation as key steps.

Selective transformation, using efficient biocatalysts, of a low value phytochemical to high value phytochemical is an exciting area of bioorganic chemistry. Sordon and coworkers ${ }^{35}$ have reported biotransformations of natural flavonoids naringenin, hesperetin, chrysin, apigenin, luteolin, quercetin, epicatechin, and biochanin A using the natural yeast, Rhodotorula glutinis. This approach produced norwogonin (5,7,8-trihydroxyflavone) from chrysin (5,7-dihydroxyflavone). Here we report a preparative scale process for biotransformation of chrysin to baicalein, via selective C6-hydroxylation using recombinant human cytochrome P450-1A1 (CYP1A1) enzyme expressed within baker's yeast (Saccharomyces cerevisiae) cells. This is the first single-step protocol for a high-yield conversion of 
63 chrysin to baicalein and, therefore, may serve as a simple and cheap strategy for production of baicalein

64 in an industrial scale.

65

66

67

68

69

70

\section{MATERIALS AND METHODS}

General. All chemicals were obtained from Sigma-Aldrich and were used as received. ${ }^{1} \mathrm{H}$ NMR spectra were recorded on Brucker-Avance DPX FT-NMR $400 \mathrm{MHz}$ instrument. Chemical data for protons are reported in parts per million (ppm) downfield from tetramethylsilane and are referenced to the residual proton in the NMR solvent $\left(\mathrm{CD}_{3} \mathrm{OD}, 3.31 \mathrm{ppm}\right)$. ESI-MS were recorded on Waters QTOF mass spectrometer.

HPLC analysis was performed on Shimadzu LC-6AD system connected with C18 column (4.6 x 25 mm, $5 \mu$ ). Mobile phase consisted of $0.1 \%$ formic acid (A) and methanol (B) using isocratic elution (30: $70-$ A: B). Flow rate was $1 \mathrm{~mL} / \mathrm{min}$ and detection wavelength was $270 \mathrm{~nm}$.

LC-MS analysis was performed on Waters Acquity UPLC system. The column used was C18, $1.7 \mu$ with dimensions of $100 \times 2.1 \mathrm{~mm}$ (column temp. $30^{\circ} \mathrm{C}$ ). Binary gradient system was used. Mobile phase A consisted of 5\% acetonitrile in water (with $0.1 \%$ formic acid). Mobile phase B consisted of acetonitrile with $0.1 \%$ formic acid. Gradient details are: Time in min (\% B concentration): 0.01 (10), 0.25 (10), 9.00 (100), 10.00 (100), 11.00 (10), 12.00 (10). PDA range: $220 \mathrm{~nm}$ to $400 \mathrm{~nm}$; flow rate: 0.3 $\mathrm{mL} / \mathrm{min}$.

Biotransformation experiment. Yeast strains, each of which contain two copies of human $C Y P 1 A 1$ or CYP1A2 genes, downstream of the $A D H 2$ promoter, integrated into chromosomal loci of the genome of the yeast strain W303-1a (ATCC 208352), were used for biotransformation (Section S2 of supporting information). Expressed CYP1A1 and CYP1A2 proteins were confirmed by Western blotting (supporting information-S4). The strains, from frozen stocks, were revived in $250 \mathrm{~mL}$ Erlenmeyer baffled flasks containing $50 \mathrm{~mL}$ YPD (Yeast, Peptone, Dextrose) medium with composition (g/L): peptone 20; yeast extract 10; glucose 15.0, $\mathrm{pH} 6.0$. The flasks were shaken at $200 \mathrm{rpm}$, at $28{ }^{\circ} \mathrm{C}$. Three 
87 consecutive YPD pre-cultures were grown for high biomass production, before addition of the substrate to cells grown in SD (Synthetic Defined) medium. Typically, loopful of CYP-containing freshly grown

89 yeast cells was inoculated in a $500 \mathrm{~mL}$ Erlenmeyer baffled flask separately containing $100 \mathrm{~mL}$ YPD 90 medium (pre-culture -1 ) at $28{ }^{\circ} \mathrm{C}$ for $24 \mathrm{~h}$. The cells were harvested after $24 \mathrm{~h}$ and inoculated into a new $91500 \mathrm{~mL}$ baffled flask containing $100 \mathrm{~mL}$ YPD medium (pre-culture -2 ) at $30{ }^{\circ} \mathrm{C}$ for $18 \mathrm{~h}$. The process 92 was repeated three times for the cells to reach an $\mathrm{OD}_{600}$, of $\sim 90$.

The harvested cells, $\sim 3.0 \mathrm{~mL}\left(\mathrm{OD}_{600}, \sim 90\right)$, were inoculated in $50 \mathrm{~mL}$ of minimal SD medium contained in a $1 \mathrm{~L}$ baffled flask. Composition of SD medium $(\mathrm{g} / \mathrm{L})$ : dextrose 1.0; dipotassium phosphate 7.0; monopotassium phosphate 2.0 ; sodium citrate 0.50 ; magnesium sulphate 0.10 ; ammonium sulphate 1.0 , $\mathrm{pH} 7.0 \pm 0.2$ at $28{ }^{\circ} \mathrm{C}$. Initially, reaction was carried out with $0.2 \mathrm{mg} / \mathrm{mL}$ of chrysin. Later, the chrysin at different concentrations viz. 0.2, 1, 2, 5 and $10 \mathrm{mg} / \mathrm{mL}$ were incubated in $50 \mathrm{~mL}$ of SD medium (DMSO was used for initial dissolution of the compound, and keeping the DMSO concentration $<0.5 \%$ in final reaction medium) for $72 \mathrm{~h}$ at $28{ }^{\circ} \mathrm{C}, 200 \mathrm{rpm}$. After every $24 \mathrm{~h}$, the medium was replenished with $1.5 \%$ w/v of glucose. For optimization of incubation time, the SD cell culture media were harvested after 24 , $10148,72,96,120,144$ and $160 \mathrm{~h}$, and were then analysed on TLC and HPLC/ LC-MS to monitor the 102 yields of biotransformation at each time point.

Isolation and characterization of baicalein. The reaction media was extracted with ethyl acetate (3 times). The combined ethyl acetate layer was concentrated on vacuo-rotavapor to obtain crude extracts that contained the biotransformation product. The crude residue was loaded on a reverse phase $(\mathrm{C} 18)$ silica gel column packed in water. The crude extract was loaded on the column by making a slurry with C18 silica gel mesh 200-400 (Sigma-Aldrich, product no. 377635). The column was then eluted with increasing concentrations of methanol in water. The desired product was collected at $50 \%$ methanol in 109 water. Evaporation of the solvent gave a yellow solid which was characterized as baicalein (1). Yellow 110 powder; m.p. $262-265{ }^{\circ} \mathrm{C}$ (Lit. $\left.264-265{ }^{\circ} \mathrm{C}\right)$; TLC: $\mathrm{R}_{\mathrm{f}}=0.5(3 \%$ methanol in DCM) and $0.8(40 \%$

111 EtOAc: hexane with 0.1\% acetic acid); ${ }^{1} \mathrm{H} \mathrm{NMR}\left(\mathrm{CD}_{3} \mathrm{OD}, 400 \mathrm{MHz}, \delta \mathrm{ppm}\right): 7.91(\mathrm{dd}, J=4.0,8.0 \mathrm{~Hz}$, 
$1122 \mathrm{H}), 7.48(\mathrm{~m}, 3 \mathrm{H}), 6.66(\mathrm{~s}, 1 \mathrm{H}), 6.55(\mathrm{~s}, 1 \mathrm{H})$; ESI-MS: $m / z 271.10[\mathrm{M}+\mathrm{H}]^{+}$. The spectral data was

113 identical to that reported in the literature ${ }^{32}$ and TLC matched with reference sample obtained from 114 Sigma-Aldrich (CAS number 491-67-8).

115 Molecular modeling: The docking of chrysin with CYP1A1 (PDB ID: 4I8V) was performed using 116 GLIDE module of Schrodinger molecular modeling software, using the protocols as described in our 117 earlier publications. ${ }^{36,} 37$ The docking protocol was validated by docking known ligand $\alpha$ 118 naphthoflavone (ANF). The interaction pattern of docked ANF and ligand from co-crystallized protein 119 (4I8V) are shown in the supporting information (Section S8).

\section{RESULTS AND DISCUSSION}

121 CYP enzymes are known for their exceptional ability to carry out hydroxylation, epoxidation or 122 demethylation reactions in a regioselective fashion, both in plants and humans. It is essential for human 123 CYP450 enzymes to be integrated on the endoplasmic reticular (ER) membranes to manifest its native 124 activity. Baker's yeast cells possess ER membranes which are not present in prokaryotic E. coli cells. 125 Eukaryotic baker's yeast cells were chosen because they can grow as rapidly as bacterial cells and they 126 are as amenable as bacteria for scale-up in fermentors. Using Baker's yeast cells, we have developed an 127 efficient technology for stable expression of human CYP enzymes within these cells. Using this 128 platform, recombinant baker's yeast cells can continue to express CYPs in shake flasks, over a week or 129 more, with increasing activities, under conditions that mimic fed-batch growth (Supporting Information; 130 S1). Microsomal CYP enzymes, isolated from these same recombinant yeast cells, have successfully 131 been used by us earlier as drug discovery tools for screening synthetic compounds and natural product 132 repositories to identify possible cancer chemopreventive agents. ${ }^{37-39}$

133 Selection of CYPs for biotransformation of chrysin. In this work, use of recombinant CYP134 expressing whole yeast cells has been explored for their ability to be used as biocatalysts for 135 biotransformation reactions. For this purpose, we chose the flavonoid chrysin as a substrate. As the 
136 cytochrome P450 family 1 enzymes CYP1A1 and CYP1A2 are reported to oxidize dietary flavonoids, ${ }^{40-}$

$137^{42}$ herein we chose two yeast-expressed enzymes of the CYP1 sub-family (i.e. CYP1A1 and CYP1A2) 138 as biocatalysts.

139 Two recombinant yeast strains, each containing two chromosomally integrated copies of CYP1A1 and 140 CYP1A2 genes under the control of the ethanol-inducible alcohol dehydrogenase $2(A D H 2)$ promoter, 141 were created to enable stable and reproducible biotransformation reactions (plasmid maps shown in 142 Supporting Information, S2). The $A D H 2$ promoter is repressed in the presence of glucose. The aim was 143 that recombinant yeast cells, containing stably integrated $C Y P$ expression cassettes, would be grown 144 initially in complete YPD medium (containing 2\% glucose) to obtain large optical density, measured at a 145 wavelength of $600 \mathrm{~nm}\left(\mathrm{OD}_{600}\right)$ of $\sim 90$, in shake flasks. This would occur without any plasmid loss and 146 would be achieved over 3 days through repetitive replenishment of glucose, every $24 \mathrm{~h}$, in the non147 selective highly nutritious YPD medium. Cells grown in YPD (Figure 1a) would then be re-suspended 148 in minimal selective SD medium ( $\mathrm{pH}$ 7.0), supplemented with $1.5 \%$ of glucose, for the 149 biotransformation reaction. It was thought that rich full YPD medium may not be appropriate for 150 biotransformation since there is a possibility of substrate binding to its ingredients.

151 For initial optimization, reactions were performed in SD with $10 \mathrm{mg}$ of chrysin in baffled flasks shaking 152 at $200 \mathrm{rpm}$ for $72 \mathrm{~h}$, at $28{ }^{\circ} \mathrm{C}$ (Figure $1 \mathrm{~b}$ ). After every $24 \mathrm{~h}$, the medium was replenished with fresh 153 glucose to a final concentration of $1.5 \%$. Glucose was exhausted after $12 \mathrm{~h}$ of growth of yeast cells when 154 it was converted to ethanol. Hence, the ethanol-inducible $A D H 2$ promoter was fully induced every $12 \mathrm{~h}$ 155 before more glucose was added to the medium for further rounds of expression.

\section{Figure 1.}

157 The reaction media at each time point was extracted with ethyl acetate. The extracts were analyzed by 158 TLC followed by HPLC/ LC-MS. The formation of new product on TLC with lower $\mathrm{R}_{\mathrm{f}}$ value than the 159 substrate gave us an indication of a hydroxylation reaction (Supporting Information, S3). LC-MS 
analysis of the reaction mixture confirmed the product as mono-hydroxy chrysin with mass of $m / z 270$.

161 The same product was formed using both the enzymes, CYP1A1 and CYP1A2, expressed within yeast 162 cells. However, conversion of substrate to product was better with CYP1A1. Therefore, for subsequent 163 scale-up experiments, only CYP1A1-expressing yeast cells were used for biotransformation.

164 Scale up and optimization of biotransformation reaction. Scale-up was performed as above; cells 165 were at first cultivated in non-selective YPD media for $72 \mathrm{~h}$, with fresh glucose $(2 \%)$ being added every $16624 \mathrm{~h}$. Cells were re-suspended in selective SD minimal medium. Chrysin at different concentrations viz. $0.2,1,2,5$ and $10 \mathrm{mg} / \mathrm{mL}$ were dissolved in DMSO and further incubated in $50 \mathrm{~mL}$ of SD medium 168 (keeping the DMSO concentration $<0.5 \%$ ) for $72 \mathrm{~h}$ at $28{ }^{\circ} \mathrm{C}, 200 \mathrm{rpm}$. The chrysin-containing cell 169 culture media were replenished with glucose every $24 \mathrm{~h}$ to a final concentration of $1.5 \%$. The reaction 170 using chrysin at concentration of $2 \mathrm{mg} / \mathrm{mL}$ (100 $\mathrm{mg}$ of chrysin) was observed to be the most efficient. 171 With 5 and $10 \mathrm{mg} / \mathrm{mL}$ concentrations, incomplete biotransformation occurred, probably because the 172 small number of cells, used for growth in these specific experiments, was inhibited by the substrate.

173 Based on these results, it was decided to optimize the time period for biotransformation. For this, we 174 chose $2 \mathrm{mg} / \mathrm{mL}$ concentration of substrate with reaction time points of 24, 48, 72, 96, 120, 144 and 160 $175 \mathrm{~h}$. HPLC analyses of the reaction mixture after 24, 48, 72, 96, 120, 144 and $160 \mathrm{~h}$ incubations indicated 176 that, at $144 \mathrm{~h}$, there was nearly complete conversion $(>92 \%)$ of chrysin to the product. The HPLC 177 chromatograms of reaction mixtures at representative four time intervals are shown in Figure 2 . In 178 HPLC analysis, the concentration of sample injected at each time interval was kept constant. The 179 increase in the AUC of baicalein with increase in the time, from $24 \mathrm{~h}$ to $144 \mathrm{~h}$, is indicative of the fact 180 that the highest amount of baicalein is formed at the $144 \mathrm{~h}$ time point.

Figure 2

182 The relative percentages (AUC) of chrysin and baicalein at different time intervals are depicted in Figure 183 3. As shown in Figure 3, the percentage conversion of chrysin to baicalein increased with time. 
184 Similarly, Figure 3b shows increased peak height (mAU) of baicalein with increase in reaction time. 185 Figures $3 \mathrm{a}$ and $3 \mathrm{~b}$, in combination, indicate that $144 \mathrm{~h}$ is the optimal reaction time for this 186 transformation. Further details of HPLC analysis are provided in supporting information, section S5.

\section{Figure 3 .}

188 Isolation and characterization of baicalein. Initial isolation attempts using normal phase silica gel 189 column chromatography showed significant loss in the product yield. Therefore, we attempted reverse 190 phase C18 silica gel column chromatography where water-methanol was used as the mobile phase. The 191 product was isolated at 50\% methanol in water and was characterized by spectral analysis and by comparison of its TLC with reference sample.

193 The ${ }^{1} \mathrm{H}$ NMR of chrysin contains a typical bunch of three singlets at chemical shift values in the range of 1946 to $7 \mathrm{ppm}$. These three singlets at $\delta 6.24,6.49$ and $6.74 \mathrm{ppm}$ correspond to the protons present at C6, 195 C8 and C3 positions. The C6-proton appears with an up-field shift in comparison to two other aromatic 196 protons at C3 and C-6, because of the shielding effect from two adjacent C5 and C7 hydroxyls. It is 197 obvious that the hydroxylation reaction is possible, either on A or C ring. Since there was no change in 198 the chemical shift value pattern of $\mathrm{C}$ ring $(\delta 7.91$, $\mathrm{dd}, 2 \mathrm{H}$ and $\delta 7.48, \mathrm{~m}, 3 \mathrm{H})$, it would indicate that the 199 C-ring is intact and no hydroxylation had taken place on this ring. The hydroxylation on A ring has two 200 possibilities, either C6- or C8 hydroxylation. Hydroxylation at C6-position will form baicalein (5,6,7201 trihydroxyflavone) whereas hydroxylation at C8-position will form norwogonin (5,7,8202 trihydroxyflavone) as a product. It was interesting to see that, in the ${ }^{1} \mathrm{H}$ NMR of the obtained product, 203 the up-field singlet $(\delta 6.24 \mathrm{ppm})$ disappeared. This singlet peak in chrysin corresponds to the proton 204 present at C6-position. This gave us a clear indication that hydroxylation occurred at the C6-position, 205 which means that the product is 5,6,7-trihydroxyflavone. This is the naturally occurring flavone, 206 commonly named as 'baicalein'. Furthermore, on comparison of the ${ }^{1} \mathrm{H}$ NMR of the obtained product 207 with norwogonin, ${ }^{35}$ the possibility of norwogonin as the product was ruled out. In literature, the 208 biotransformation of chrysin using natural yeast, Rhodotorula glutinis yielded C-8 hydroxylated product 
209 norwogonin, ${ }^{35}$ however in the present study, C-6 hydroxylated product (baicalein) was formed, which

210 may be possibly because of the regio-specificity of the CYP1A1 enzyme.

211 Mass analysis of the isolated product showed $\mathrm{m} / \mathrm{z}$ peak at 271 in ES+ve mode, which matched with the 212 predicted product. The final confirmation of the assigned product was done by co-TLC and HPLC 213 analysis with the reference standard of baicalein (CAS number: 491-67-8)' purchased from Sigma214 Aldrich. TLC images as well as HPLC analysis clearly matched the reference standard (TLC images are 215 shown in Supporting Information -S3).

216 The LC-MS analysis was also performed for the extract as well as isolated baicalein (Figure 4).

Figure 4.

Docking of chrysin with CYP1A1. In order to decipher the rationale for regioselective hydroxylation, 219 chrysin was docked with the substrate binding site of CYP1A1 enzyme (PDB ID: 4I8V). The interaction pattern of chrysin with CYP1A1 is depicted in Figure 5. It is interesting to note that the A-ring of chrysin orients towards the heme. Furthermore, the C-6 carbon of A-ring is present in close-proximity

with heme protein, suggesting that the reactive heme-oxo intermediate should possibly form at this position. Other key interactions which help in stabilizing this orientation of chrysin includes: (a) hydrophobic $\pi-\pi$ interactions of Phe-224 of I-helix with B and C rings; (b) $\pi-\pi$ interactions of Phe-123 with A ring; and (c) polar H-bonding of C-7 hydroxyl group with Ser-122. This observed orientation, excludes the possibility of hydroxylation at $\mathrm{C}-8$ and at aromatic $\mathrm{CH}$ of $\mathrm{B}$ and $\mathrm{C}$ rings.

Our efforts using yeast whole cells have resulted in the development of a reproducible preparative-scale biotransformation process for the conversion of chrysin to baicalein (5,6,7-trihydroxyflavone).

230 According to the literature, the medicinal effects of baicalein are more profound than that of chrysin. 231 Furthermore, commercially available baicalein is at least 60-times more expensive than chrysin. Thus, 
232 this protocol described here can be utilized for production of a high value phytochemical from a low 233 value one, using a simple, low-cost, one-step biotransformation reaction.

234 In conclusion, we have demonstrated the ability of whole yeast cells, that overexpress the human 235 CYP1A1 enzyme, to catalyse biotransformation of $>92 \%$ of the natural flavonoid chrysin to baicalein. 236 Optimal aeration, neutral $\mathrm{pH}$ and maintenance of glucose concentration, throughout the reaction, played 237 very important roles in the biotransformation reaction. The example demonstrated in this paper, 238 provides an opportunity for further exploring the utility of stable recombinant CYP enzyme-expressing 239 yeast cells for industrial production of medicinally important polyphenolic compounds.

\section{ASSOCIATED CONTENT}

241 Supporting Information. Additional experimental details. This material is available free of charge via 242 the Internet at http://pubs.acs.org

243 AUTHOR INFORMATION

244 Corresponding Author

$245 \quad *$ Tel: +91-191-2585006. Fax: +91-191-2586333. E-mail: sbharate@iiim.ac.in, 246 sandipbharate@gmail.com (S.B.B.)

247 *Tel: +91-191-2585006. Fax: +91-191-2586333. E-mail: ssaran@iiim.ac.in (SS)

248 *Tel: 44(0)116 250 7280; Fax: +44(0) 116257 7287; E-mail: bchaudhuri@dmu.ac.uk (B.C.)

\section{ORCID}

250 Ram A. Vishwakarma: 0000-0002-0752-6238

251 Sandip B. Bharate: 0000-0001-6081-5787

252 Author Contributions

253 The enzyme expression in yeast cells was executed by I. S. Williams, L. Gatchie and B. Chaudhuri. Pre254 culturing of yeast cells and their growth in SD medium followed by set-up of biotransformation 255 experiment was performed by S. Chib and S. Saran. Product isolation and characterization was done by 
256 V. Nuthakki, R.A. Vishwakarma and S. B. Bharate. LS-MS analysis was done by N.A. Narkhede and 257 molecular modeling by P. Joshi and S.B. Bharate.

258 Funding

259 This work was supported by CSIR $12^{\text {th }}$ five year plan project BSC-0205 (S.B.B.) and Higher Education 260 Innovation Fund (HEIF) (B.C.).

\section{$261 \quad$ Notes}

262 The authors declare no competing financial interest.

263

264 ABBREVIATIONS

265 ADH2, alcohol dehydrogenase 2; ANF, alpha-naphthoflavone; CYP1A1, cytochrome P450 group 266 enzyme 1A1; CYP1A2, cytochrome P450 group enzyme 1A2; DMSO, dimethyl sulfoxide; ER, 267 endoplasmic reticulum; HPLC, high performance liquid chromatography; LC-MS, liquid 268 chromatography mass spectrometry; OD, optical density; PDB, protein data bank; SD, Synthetic 269 Defined; TLC, thin-layer chromatography; YPD, Yeast, Peptone, Dextrose;

\section{ACKNOWLEDGMENT}

272 SBB and BC thank CSIR 12 ${ }^{\text {th }}$ FYP project BSC-0205 and Higher Education Innovation Fund (HEIF) for 273 financial support.

\section{REFERENCES}

275 1. Papafragkakis, C.; Ona, M. A.; Reddy, M.; Anand, S. Acute Hepatitis after Ingestion of a 276 Preparation of Chinese Skullcap and Black Catechu for Joint Pain. Case Reports Hepatol. 2016, 277 2016, Article ID: 4356749 
278 2. Roy, M. K.; Nakahara, K.; Na, T. V.; Trakoontivakorn, G.; Takenaka, M.; Isobe, S.; Tsushida, T. Baicalein, a flavonoid extracted from a methanolic extract of Oroxylum indicum inhibits proliferation of a cancer cell line in vitro via induction of apoptosis. Pharmazie 2007, 62, 149153.

3. Zhou, R. T.; He, M.; Yu, Z.; Liang, Y.; Nie, Y.; Tai, S.; Teng, C. B. Baicalein inhibits pancreatic cancer cell proliferation and invasion via suppression of NEDD9 expression and its downstream Akt and ERK signaling pathways. Oncotarget 2017, DOI: 10.18632/oncotarget.16912.

4. Wang, Y. F.; Xu, Y. L.; Tang, Z. H.; Li, T.; Zhang, L. L.; Chen, X.; Lu, J. H.; Leung, C. H.; Ma, D. L.; Qiang, W. A.; Wang, Y. T.; Lu, J. J. Baicalein Induces Beclin 1- and Extracellular SignalRegulated Kinase-Dependent Autophagy in Ovarian Cancer Cells. Am J Chin Med 2017, 45, 123-136.

5. Palko-Labuz, A.; Sroda-Pomianek, K.; Uryga, A.; Kostrzewa-Suslow, E.; Michalak, K.

6. Chai, Y.; Xu, J.; Yan, B. The anti-metastatic effect of baicalein on colorectal cancer. Oncol Rep

7. Bie, B.; Sun, J.; Li, J.; Guo, Y.; Jiang, W.; Huang, C.; Yang, J.; Li, Z. Baicalein, a Natural AntiAnticancer activity of baicalein and luteolin studied in colorectal adenocarcinoma LoVo cells and in drug-resistant LoVo/Dx cells. Biomed Pharmacother 2017, 88, 232-241. 2017, 37, 2317-2323. Cancer Compound, Alters MicroRNA Expression Profiles in Bel-7402 Human Hepatocellular Carcinoma Cells. Cell Physiol Biochem 2017, 41, 1519-1531.

8. Rui, X.; Yan, X. I.; Zhang, K. Baicalein inhibits the migration and invasion of colorectal cancer cells via suppression of the AKT signaling pathway. Oncol Lett 2016, 11, 685-688.

9. Nguyen, L. T.; Song, Y. W.; Cho, S. K. Baicalein Inhibits Epithelial to Mesenchymal Transition via Downregulation of Cyr61 and LOXL-2 in MDA-MB231 Breast Cancer Cells. Mol Cells 2016, 39, 909-914. 
302 10. Mu, J.; Liu, T.; Jiang, L.; Wu, X.; Cao, Y.; Li, M.; Dong, Q.; Liu, Y.; Xu, H. The Traditional Chinese Medicine Baicalein Potently Inhibits Gastric Cancer Cells. J Cancer 2016, 7, 453-461.

11. Ma, X.; Yan, W.; Dai, Z.; Gao, X.; Ma, Y.; Xu, Q.; Jiang, J.; Zhang, S. Baicalein suppresses metastasis of breast cancer cells by inhibiting EMT via downregulation of SATB1 and Wnt/betacatenin pathway. Drug Des Devel Ther 2016, 10, 1419-1441.

12. Choi, E. O.; Park, C.; Hwang, H. J.; Hong, S. H.; Kim, G. Y.; Cho, E. J.; Kim, W. J.; Choi, Y. 308

H. Baicalein induces apoptosis via ROS-dependent activation of caspases in human bladder cancer 5637 cells. Int J Oncol 2016, 49, 1009-1018.

14. Guo, Z.; Hu, X.; Xing, Z.; Xing, R.; Lv, R.; Cheng, X.; Su, J.; Zhou, Z.; Xu, Z.; Nilsson, S.; Liu,

Z. Baicalein inhibits prostate cancer cell growth and metastasis via the caveolin-1/AKT/mTOR pathway. Mol Cell Biochem 2015, 406, 111-119.

15. Zheng, Y. H.; Yin, L. H.; Grahn, T. H.; Ye, A. F.; Zhao, Y. R.; Zhang, Q. Y. Anticancer effects

16. Li, H. L.; Zhang, S.; Wang, Y.; Liang, R. R.; Li, J.; An, P.; Wang, Z. M.; Yang, J.; Li, Z. F. Baicalein induces apoptosis via a mitochondrial-dependent caspase activation pathway in T24 bladder cancer cells. Mol Med Rep 2013, 7, 266-270.

17. Kim, D. H.; Hossain, M. A.; Kang, Y. J.; Jang, J. Y.; Lee, Y. J.; Im, E.; Yoon, J. H.; Kim, H. S.;

Chung, H. Y.; Kim, N. D. Baicalein, an active component of Scutellaria baicalensis Georgi, induces apoptosis in human colon cancer cells and prevents AOM/DSS-induced colon cancer in mice. Int J Oncol 2013, 43, 1652-1658. 
325 18. Kim, S. J.; Kim, H. J.; Kim, H. R.; Lee, S. H.; Cho, S. D.; Choi, C. S.; Nam, J. S.; Jung, J. Y. Antitumor actions of baicalein and wogonin in HT-29 human colorectal cancer cells. Mol Med Rep 2012, 6, 1443-1449.

19. Chen, C. H.; Huang, T. S.; Wong, C. H.; Hong, C. L.; Tsai, Y. H.; Liang, C. C.; Lu, F. J.; Chang,

20. Motoo, Y.; Sawabu, N. Antitumor effects of saikosaponins, baicalin and baicalein on human

21. Bonham, M.; Posakony, J.; Coleman, I.; Montgomery, B.; Simon, J.; Nelson, P. S. hepatoma cell lines. Cancer Lett 1994, 86, 91-95.

W. H. Synergistic anti-cancer effect of baicalein and silymarin on human hepatoma HepG2 Cells. Food Chem Toxicol 2009, 47, 638-644.

Characterization of chemical constituents in Scutellaria baicalensis with antiandrogenic and growth-inhibitory activities toward prostate carcinoma. Clin. Cancer Res. 2005, 11, 3905-3914.

22. Ma, Z.; Otsuyama, K.; Liu, S.; Abroun, S.; Ishikawa, H.; Tsuyama, N.; Obata, M.; Li, F. J.; Zheng, X.; Maki, Y.; Miyamoto, K.; Kawano, M. M. Baicalein, a component of Scutellaria radix from Huang-Lian-Jie-Du-Tang (HLJDT), leads to suppression of proliferation and induction of apoptosis in human myeloma cells. Blood 2005, 105, 3312-3318.

23. Liu, H.; Dong, Y.; Gao, Y.; Du, Z.; Wang, Y.; Cheng, P.; Chen, A.; Huang, H. The Fascinating Effects of Baicalein on Cancer: A Review. Int J Mol Sci 2016, 17, pii: E1681.

24. Gao, Y.; Snyder, S. A.; Smith, J. N.; Chen, Y. C. Anticancer properties of baicalein: a review. Med Chem Res 2016, 25, 1515-1523.

25. Li, J.; Ma, J.; Wang, K. S.; Mi, C.; Wang, Z.; Piao, L. X.; Xu, G. H.; Li, X.; Lee, J. J.; Jin, X. Baicalein inhibits TNF-alpha-induced NF-kappaB activation and expression of NF-kappaBregulated target gene products. Oncol Rep 2016, 36, 2771-2776. 
347 26. Patwardhan, R. S.; Sharma, D.; Thoh, M.; Checker, R.; Sandur, S. K. Baicalein exhibits anti348 inflammatory effects via inhibition of NF-kappaB transactivation. Biochem Pharmacol 2016, $108,75-89$.

27. Tsai, K. L.; Hung, C. H.; Chan, S. H.; Shih, J. Y.; Cheng, Y. H.; Tsai, Y. J.; Lin, H. C.; Chu, P. M. Baicalein protects against oxLDL-caused oxidative stress and inflammation by modulation of AMPK-alpha. Oncotarget 2016, 7, 72458-72468.

28. Zhao, F.; Fu, L.; Yang, W.; Dong, Y.; Yang, J.; Sun, S.; Hou, Y. Cardioprotective effects of baicalein on heart failure via modulation of $\mathrm{Ca}(2+)$ handling proteins in vivo and in vitro. Life Sci 2016, 145, 213-223.

29. Sahu, B. D.; Mahesh Kumar, J.; Sistla, R. Baicalein, a Bioflavonoid, Prevents Cisplatin-Induced Acute Kidney Injury by Up-Regulating Antioxidant Defenses and Down-Regulating the MAPKs and NF-kappaB Pathways. PLoS One 2015, 10, e0134139.

30. Zhang, W.; Yi, D.; Gao, K.; Liu, M.; Yang, J.; Liao, X.; Yang, B. Hydrolysis of scutellarin and related glycosides to scutellarein and the corresponding aglycones. J. Chem. Res. 2014, 38, 396398.

31. Kim, D. H.; Yun, C. H.; Kim, M. H.; Kumar, C. N.; Yun, B. H.; Shin, J.-S.; An, H. J.; Lee, Y. 363 H.; Yun, Y. D.; Rim, H.-K.; Yoo, M.-S.; Lee, K.-T.; Lee, Y. S. 4'-Bromo-5,6,7suppressing the NF-kB signaling pathway in RAW 264.7 macrophages. Bioorg. Med. Chem.

32. Chen, D. Z.; Yang, J.; Yang, B.; Wu, Y. S.; Wu, T. Total synthesis of baicalein. J Asian Nat Prod Res 2010, 12, 124-128. 
369 33. Vyas, B.; Singh, M.; Kaur, M.; Silakari, O.; Bahia, M. S.; Singh, B. Pharmacophore and docking-based hierarchical virtual screening for the designing of aldose reductase inhibitors: synthesis and biological evaluation. Med Chem Res 2016, 25, 609-626.

34. Righi, G.; Antonioletti, R.; Silvestri, I. P.; D’Antona, N.; Lambusta, D.; Bovicelli, P. Convergent synthesis of mosloflavone, negletein and baicalein from crysin. Tetrahedron 2010, 66, 12941298.

36. Joshi, P.; McCann, G. J. P.; Sonawane, V. R.; Vishwakarma, R. A.; Chaudhuri, B.; Bharate, S.

37. Horley, N. J.; Beresford, K. J. M.; Chawla, T.; McCann, G. J. P.; Ruparelia, K. C.; Gatchie, L.; Sonawane, V. R.; Williams, I. S.; Tan, H. L.; Joshi, P.; Bharate, S. S.; Kumar, V.; Bharate, S. B.; Chaudhuri, B. Discovery and characterization of novel CYP1B1 inhibitors based on heterocyclic chalcones: Overcoming cisplatin resistance in CYP1B1-overexpressing lines. Eur. J. Med. Chem. 2017, 129, 159-174.

38. Mohd Siddique, M. U.; McCann, G. J. P.; Sonawane, V. R.; Horley, N.; Gatchie, L.; Joshi, P.; Bharate, S. B.; Jayaprakash, V.; Sinha, B. N.; Chaudhuri, B. Quinazoline derivatives as selective CYP1B1 inhibitors. Eur. J. Med. Chem. 2017, 130, 320-327.

39. Mohd Siddique, M. U.; McCann, G.; Sonawane, V.; Horley, N.; Williams, I. S.; Joshi, P.; Bharate, S. B.; Jayaprakash, V.; Sinha, B. N.; Chaudhuri, B. Biphenyl urea derivatives as selective CYP1B1 inhibitors. Org. Biomol. Chem. 2016, 14, 8931-8936. 
393 40. Okate, Y.; Walle, T. Oxidation of the flavonoids galangin and kaempferide by human liver 394 microsomes and CYP1A1, CYP1A2, and CYP2C9. Drug Metab. Disp. 2002, 30, 103-105.

395 41. Hamada, M.; Satsu, H.; Ashida, H.; Sugita-Konishi, Y.; Shimizu, M. Metabolites of galangin by 396 2,3,7,8-tetrachlorodibenzo-p-dioxin-inducible cytochrome P450 1A1 in human intestinal 397 epithelial Caco-2 cells and their antagonistic activity toward aryl hydrocarbon receptor. J. Agric. $398 \quad$ Food Chem. 2010, 58, 8111-8118.

399 42. Ciolino, H. P.; Daschner, P. J.; Yeh, G. C. Dietary flavonols quercetin and kaempferol are 400 ligands of the aryl hydrocarbon receptor that affect CYP1A1 transcription differentially. Biochem $401 \quad$ J. 1999, 340, 715-722.

402

403 404 


\section{FIGURE LEGENDS}

Figure 1. (a) CYP1A1-expressing cells grown in YPD Medium in test-tubes; (b) Biotransformation reaction using CYP1A1 in SD medium in shake-flasks; (c) scheme showing conversion of chrysin to baicalein, and their key ${ }^{1} \mathrm{H}$ NMR chemical shift values

Figure 2. HPLC analysis of biotransformation reaction at different time intervals. (a) HPLC chromatogram of chrysin reference standard; (b) HPLC chromatogram of baicalein reference standard; (c) HPLC chromatogram of biotransformation reaction after 24 hrs of incubation time; (d) HPLC chromatogram of biotransformation reaction after $48 \mathrm{hrs}$ of incubation time; (e) HPLC chromatogram of biotransformation reaction after 96 hrs of incubation time; (f) HPLC chromatogram of biotransformation reaction after $144 \mathrm{hrs}$ of incubation time. The concentration of sample injected is kept constant at each time interval; therefore an increase in AUC (and peak height) with the increase in incubation time indicates progress of the reaction.

Figure 3. (a) Relative percentage $( \pm \mathrm{SD})$ of chrysin and baicalein at different time intervals during a typical biotransformation reaction (the percentages are based on the AUC of the peaks in HPLC analysis at $270 \mathrm{~nm})$. (b) Baicalein $\left(t_{\mathrm{R}}=5.99 \mathrm{~min}\right)$ peak height $( \pm \mathrm{SD})$ at different time intervals during biotransformation reaction.

Figure 4. LC-MS analysis of reaction mixture at $144 \mathrm{~h}$. (a) LC chromatogram of reaction mixture after $144 \mathrm{~h}$ of incubation. (B) LC chromatogram of isolated product; (c) Mass spectra of peak at $t_{\mathrm{R}} 4.69 \mathrm{~min}$.

Figure 5. Molecular docking of chrysin with CYP1A1 (PDB: 4I8V), showing the predicted site of hydroxylation as C6. 
(a)
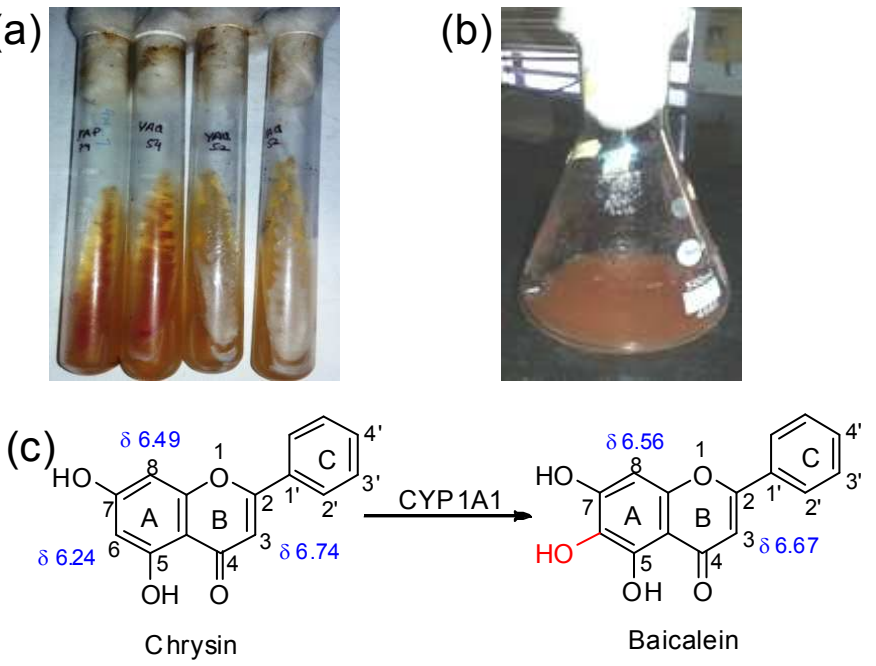

Figure 1. 

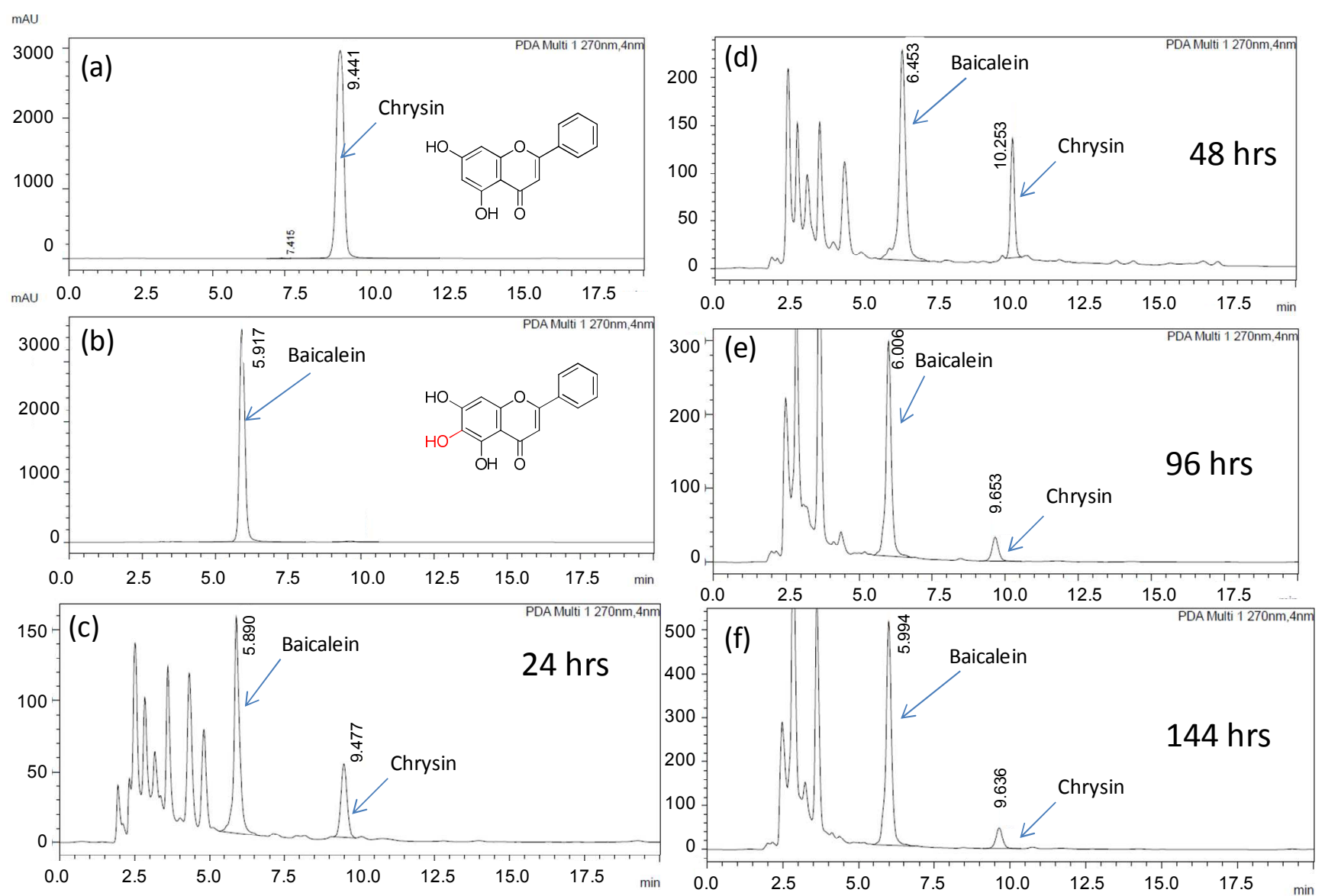

Figure 2. 


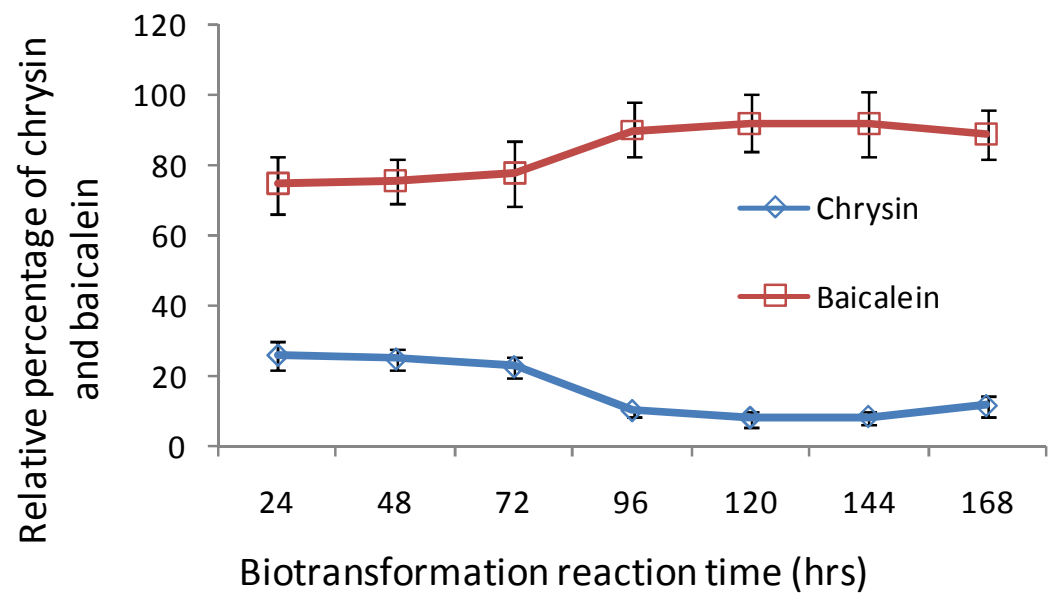

(a)

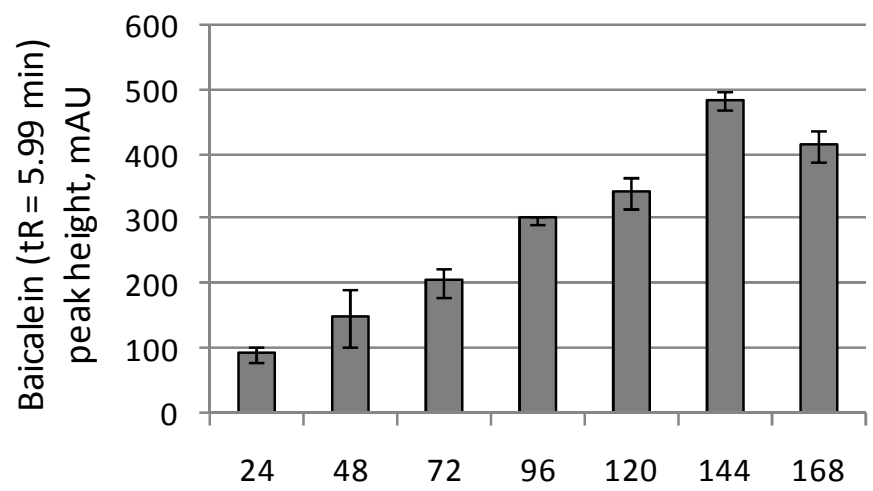

Biotransformation reaction time (hrs)

(b)

Figure 3. 

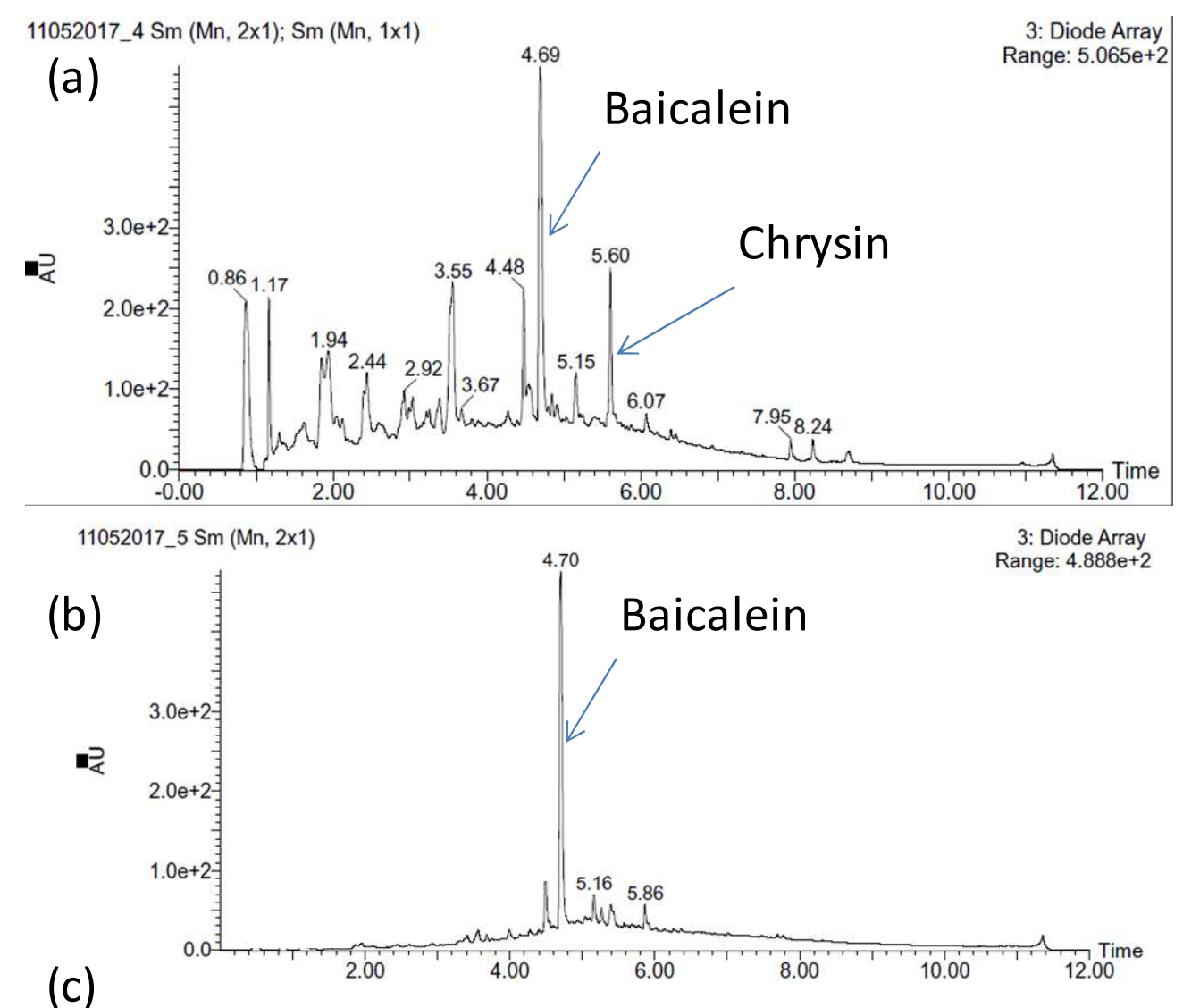

11052017_5 274 (4.756) Cn (Cen,2, 80.00, Ht); Sm (Mn, 5x0.75); Cm (273:276)

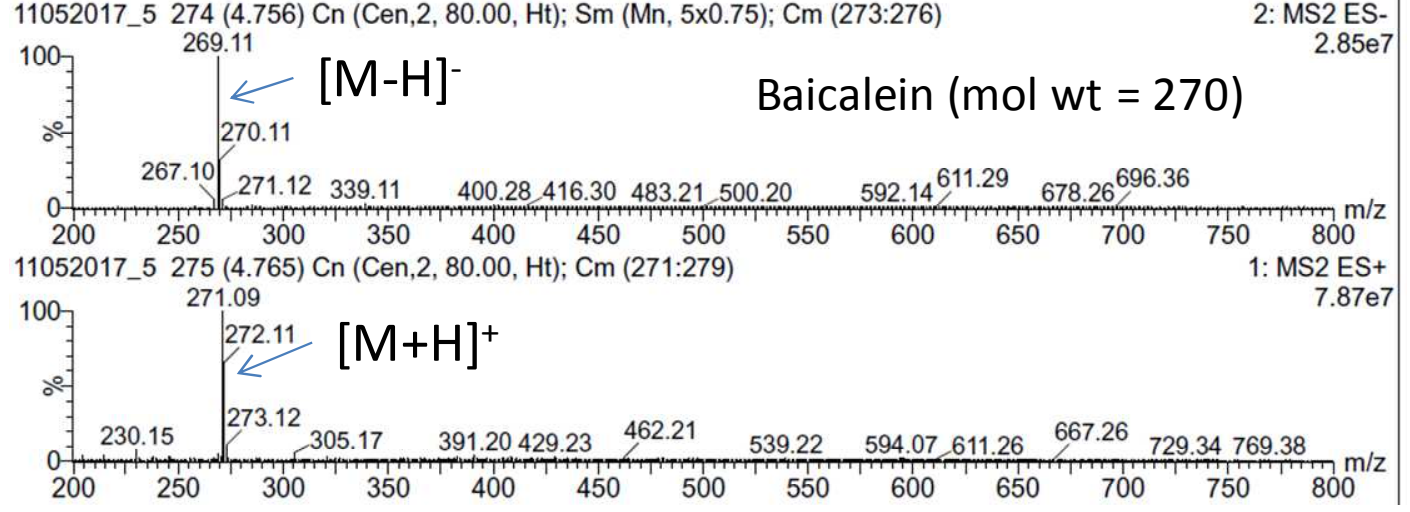

\section{Figure 4.}




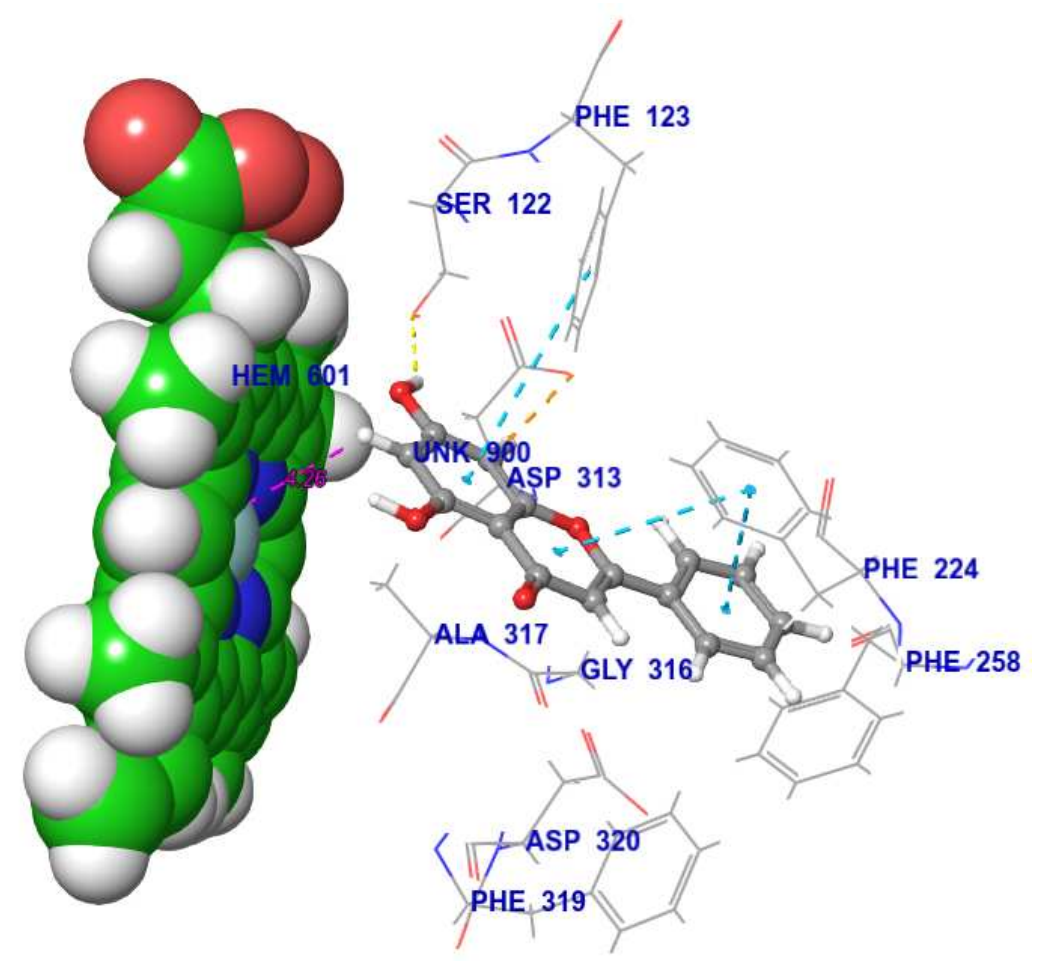

Figure 5. 


\section{TOC graphic}
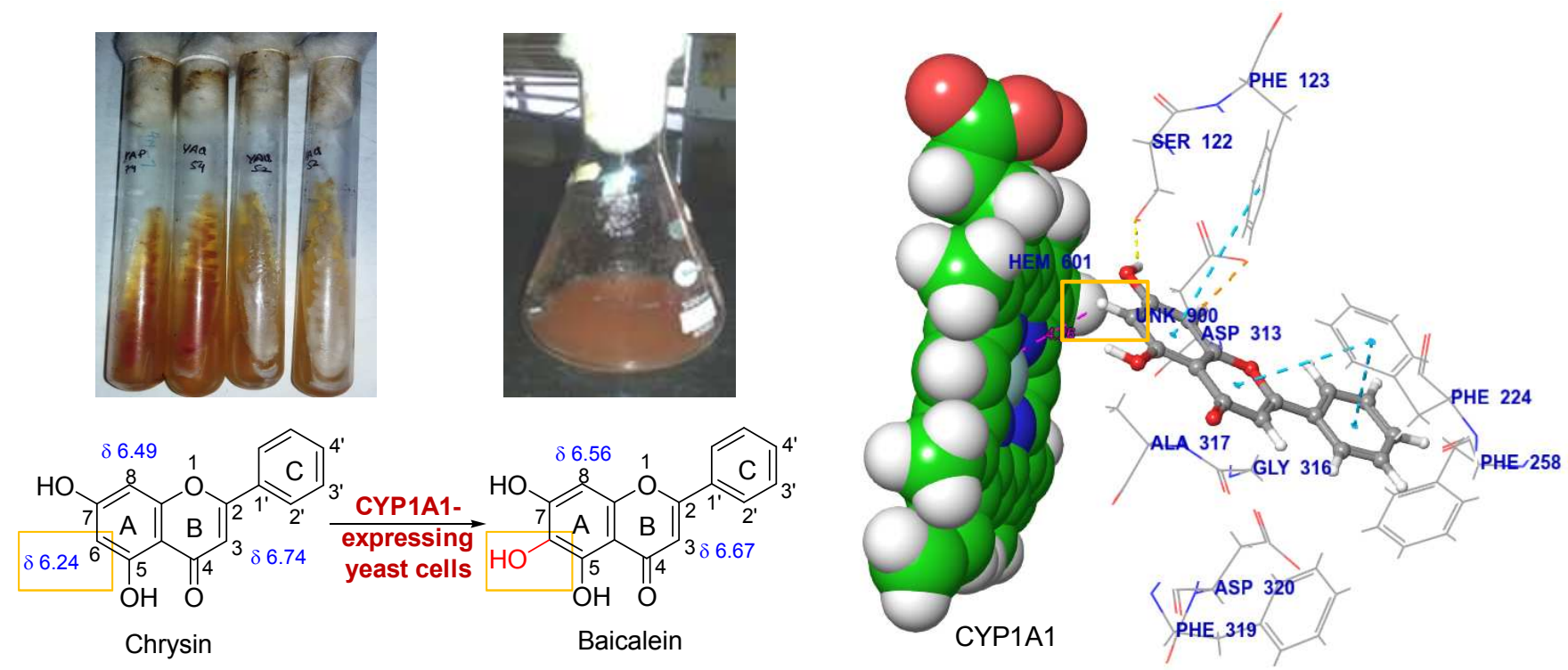